\title{
Hematoma epidural medular como complicación de trombólisis en un paciente con infarto del miocardio
}

\author{
Medullary epidural hematoma as a complication of thrombolysis in a patient with \\ myocardial infarction
}

\author{
Meredith Agüero-Castrellón ${ }^{1 *}$, Fernando M. Calderón-Osorio ${ }^{1}$, Josué B. Zamarripa-Mottú \\ Nundehui Cisneros-Sánchez', Luis A. Sierra-Rodríguez ${ }^{1}$ y José M. Meza-Alvarado ${ }^{1}$ \\ ${ }^{1}$ Departamento de Cardiología Clínica; ${ }^{2}$ Departamento de Hemodinamia e Intervencionismo. Unidad Médica de Alta Especialidad No. 71 , Instituto \\ Mexicano del Seguro Social, Torreón, Coahuila, México
}

\begin{abstract}
La terapia trombolítica es una de las estrategias de reperfusión del infarto agudo de miocardio con elevación del segmento ST. Entre sus complicaciones destacan las hemorragias, con una incidencia de hemorragia mayor de hasta el 8\%${ }^{1}$. El Registro Nacional de Síndromes Coronarios Agudos (RENASICA II) señala una incidencia de hemorragia mayor entre el $1 \%$ y el $2 \%{ }^{2}$.

Resulta difícil establecer una incidencia real debido
\end{abstract} a la heterogeneidad de definiciones de sangrado mayor $^{3}$. EI RENASICA III define el sangrado mayor como sangrado fatal, retroperitoneal documentado, sangrado intracraneal 0 intraocular, sangrado que resulta en compromiso hemodinámico que requiera tratamiento específico, sangrado que requiera tratamiento quirúrgico o descompresión de un espacio cerrado para controlar el evento, cualquier transfusión $>1$ unidad de concentrado eritrocitario o sangre completa, caída de hemoglobina $>3 \mathrm{mg} / \mathrm{dl}$ o caída del hematocrito $>10 \% 4$.

Dentro de los factores predisponentes para el sangrado se encuentran los parámetros clínicos, farmacológicos y relacionados con los procedimientos invasivos, de los cuales los de mayor impacto son la edad, el sexo femenino, el antecedente de sangrado y anemia, la insuficiencia renal, la presentación con choque cardiogénico, el uso de procedimientos invasivos y el tratamiento con inhibidores de la glucoproteína Ilb/llla ${ }^{3}$.

\section{Caso clínico}

Hombre de 65 años con antecedentes de hipertensión arterial, etilismo social, tabaquismo, sedentarismo y obesidad. Acudió a urgencias por dolor torácico típico. Se realizó electrocardiograma de 12 derivaciones que llevó al diagnóstico de infarto de miocardio con elevación del segmento ST, el cual se trombolizó con tenecteplasa. Al no mostrar criterios de reperfusión, se envió a nuestra unidad de hemodinámica para intervención coronaria percutánea de rescate, donde se recibió con dolor cervical. Se realizó angioplastia exitosa en la arteria descendente anterior y continuó vigilancia en la unidad de cuidados coronarios, para posteriormente ser egresado a piso de cardiología. Durante sus primeras horas se agregaron al dolor manifestaciones neurológicas, con rápido

\section{Correspondencia:}

*Meredith Agüero-Castrellón

E-mail: mere21_06@ hotmail.com
Fecha de recepción: 07-02-2020

Fecha de aceptación: 16-06-2020 DOI: $10.24875 /$ ACM.20000048
Disponible en internet: 23-11-2020 Arch Cardiol Mex. 2021;91(2):255-257 www.archivoscardiologia.com 1405-9940 / @ 2020 Instituto Nacional de Cardiología Ignacio Chávez. Publicado por Permanyer. Este es un artículo open access bajo la licencia CC BY-NC-ND (http://creativecommons.org/licenses/by-nc-nd/4.0/). 


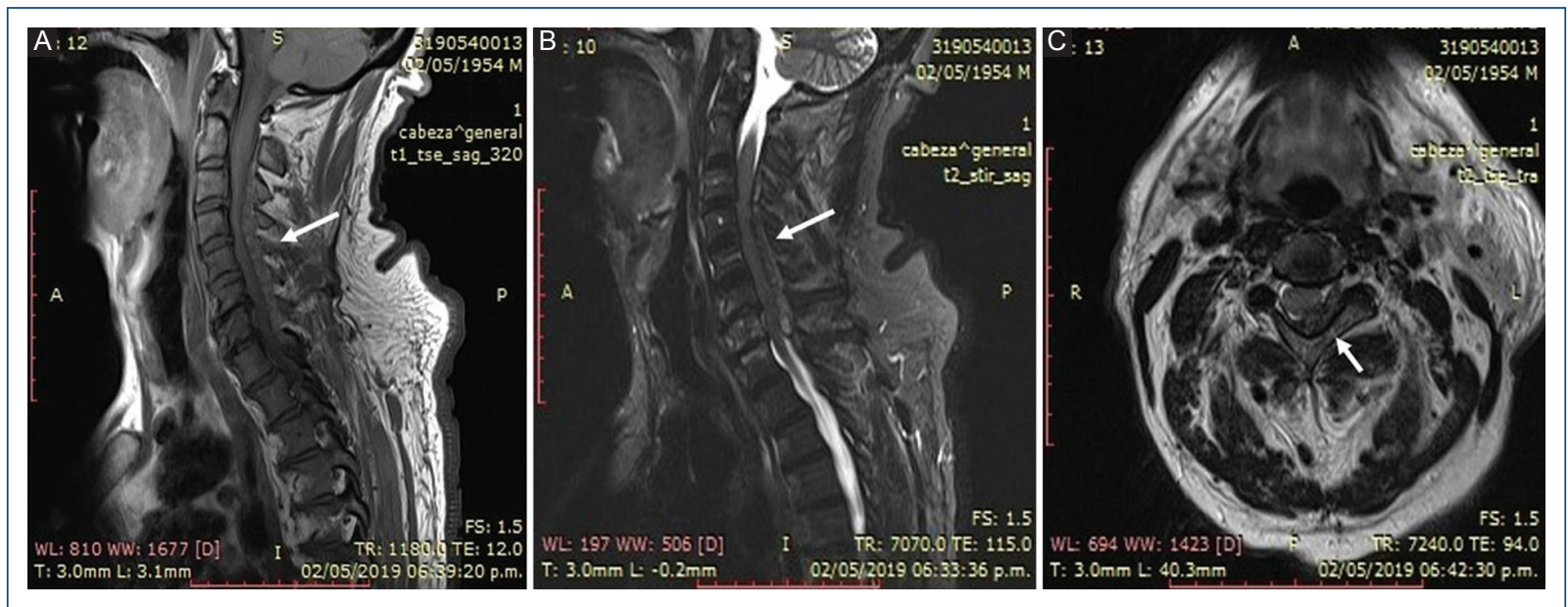

Figura 1. Imágenes de resonancia magnética de columna cervicotorácica en corte sagital que muestran una lesión en el canal medular que se extiende de C2 a C5 (flechas). A: ponderación en T1. B: ponderación en T2. C: corte transversal a nivel de C3, imagen ponderada en T2, que muestra una zona hipointensa con efecto de compresión medular en relación con un hematoma.

deterioro sensitivo y motor en las cuatro extremidades hasta desarrollar síndrome medular completo. Se solicitó resonancia magnética que reveló lesión intrarraquídea con compresión medular cervical en relación con hematoma epidural en C2-C5 (Fig. 1). Presentó deterioro hemodinámico y respiratorio con necesidad de apoyo con norepinefrina e intubación endotraqueal. Se realizó laminectomía descompresiva de C6 para permanecer en vigilancia en la unidad de cuidados intensivos y posteriormente en piso de cardiología, donde continuó con evolución hacia la mejoría. Finalmente, fue egresado con hemiplejia izquierda como secuela.

\section{Discusión}

La incidencia de hemorragia mayor por trombólisis se ha reportado del $6.3 \%$ para la estreptoquinasa, el $5.4 \%$ para la alteplasa y el $4.7 \%$ para la tenecteplasa ${ }^{1}$. El estudio ASSENT-2 mostró que la tenecteplasa se asoció a una menor tasa de hemorragia mayor que la alteplasa (4.7 vs. $5.9 \% ; p=0.0002)^{1,5}$.

Se estima una incidencia de hematoma epidural espontáneo del $0.1 \%$; se asocia a trauma, coagulopatía, malformaciones arteriovenosas, tumores o infecciones. No existen estadísticas sobre la incidencia de hematoma epidural espontáneo asociado al tratamiento fibrinolítico debido a su baja frecuencia, pero se han reportado algunos casos secundarios al uso de activador del plasminógeno tisular 6,7 .
En caso de hematoma espinal, el inicio de los síntomas en general es súbito y con una rápida progresión. Típicamente los pacientes se presentan con cervicalgia intensa y signos de compresión medular. El diagnostico se confirma con resonancia magnética y el tratamiento es mediante descompresión quirúrgica del canal medular ${ }^{6}$.

El pronóstico depende del nivel de afectación y del tiempo de evolución ${ }^{6}$. La mejoría posquirúrgica ocurre en el $95 \%$ de las lesiones sensitivomotoras incompletas y en el $45 \%$ de las lesiones con pérdida sensitivomotora completa?.

\section{Conclusiones}

El hematoma medular como complicación de la trombólisis es sumamente infrecuente. Deberá sospecharse ante la presencia de dolor cervical o dorsal tras la trombólisis. El reconocimiento precoz y la confirmación mediante resonancia magnética son cruciales para establecer el tratamiento oportuno y mejorar el pronóstico.

\section{Agradecimientos}

A todos los médicos adscritos y médicos residentes de los departamentos de cardiología clínica, hemodinamia e intervencionismo, neurología clínica, imagenología, neurocirugía y unidad de cuidados intensivos 
coronarios y adultos involucrados en la atención y la resolución oportuna del presente caso.

\section{Financiamiento}

No se recibió ningún tipo de financiamiento para el presente trabajo.

\section{Conflicto de intereses}

Los autores declaran no tener ningún conflicto de intereses.

\section{Responsabilidades éticas}

Protección de personas y animales. Los autores declaran que para esta investigación no se han realizado experimentos en seres humanos ni en animales.

Confidencialidad de los datos. Los autores declaran que en este artículo no aparecen datos de pacientes.
Derecho a la privacidad y consentimiento informado. Los autores declaran que en este artículo no aparecen datos de pacientes.

\section{Bibliografía}

1. Echavarría M, Juárez U, Meillón L, Martínez C. Complicaciones hemorrágicas del tratamiento de los síndromes coronarios agudos. Arch Cardiol Mex. 2011;81:228-39.

2. García A, Jerjes C, Martínez P, Azpiri JR, Autrey A, Martínez C, et al. RENASICA II Registro Mexicano de Síndromes Coronarios Agudos. Arch Cardiol Mex. 2005;75:S6-S19.

3. Sánchez M, Manzano S, Valdes M. ¿Por qué debemos estratificar el riesgo hemorrágico junto con el isquémico en el síndrome coronario agudo? Rev Esp Cardiol Supl. 2014;14(A):10-7.

4. Jerjes C, Martínez C, Borrayo G, Carrillo J, Juárez U, Quintanilla J. Third national registry of acute coronary syndromes (RENASICA III). Arch Cardiol Mex. 2015;85:207-14.

5. Assessment of the Safety and Efficacy of a New Thrombolytic (ASSENT-2) Investigators, Van De Werf F, Adgey J, Ardissino D, Armstrong PW, Aylward P, Barbash G, et al. Single-bolus tenecteplase compared with front-loaded alteplase in acute myocardial infarction: the ASSENT-2 double-blind randomised trial. Lancet. 1999;354:716-22.

6. Salehpour F, Mirzaei F, Kazemzadeh M, Alavi SAN. Spontaneous epidural hematoma of cervical spine. Int J Spine Surg. 2018;12:26-9.

7. Sawin PD, Traynelis VC, Follett KA. Spinal epidural hematoma following coronary thrombolysis with tissue plasminogen activator. Report of two cases. J Neurosurg. 1995;83:350-3. 